\title{
Compassion in Buddhist Psychology
}

\author{
By John Makransky, PhD
}

Chapter Four in Compassion and Wisdom in Psychotherapy, edited by Christopher K. Germer and Ronald D. Siegel, Guilford Press, 2012

John Makransky is a scholar of Indian and Tibetan Buddhism. His chapter examines compassion in three leading traditions of Buddhism. In early and Theravada Buddhism, compassion is a power for deep mental purification, protection and healing that supports inner freedom. In Mahayana Buddhism, compassion becomes the primary means to empower and communicate a non-conceptual wisdom in which self and others are sensed as undivided. In Vajrayana Buddhism, unconditional compassion radiates forth all-inclusively as a spontaneous expression of the mind's deepest unconditioned nature. Within this discussion, John will give examples of techniques from these traditions for cultivating compassion.

"We might reject everything else: religion, ideology, all received wisdom. But we cannot escape the necessity of love and compassion."

-His Holiness the Dalai Lama

In Buddhist psychology, compassion is a form of empathy. We sense others' suffering as like our own and naturally wish them deep freedom from it. A compassionate mind, as opposed to a cruel and angry one, is understood to be much more closely attuned to our actual condition. Thus, compassion is informed by the wisdom that understands our basic situation: the inner causes of our suffering and our potential for freedom and goodness. From a Buddhist perspective, compassion with wisdom is the foundation of emotional healing.

Compassion is also characterized as a mental capacity that, when cultivated and strengthened, empowers all positive states of mind as we awaken to our fullest human potential. In Buddhist psychology, the patterns of our experience unfold based on our habits of intention and reaction. "All phenomena of experience have mind as their 
forerunner, mind as chief, and they are mind-made." (Dhammapada chapter 1, vss. 1, 2). Thus, a loving, compassionate state of mind supports our own happiness and well-being and helps bring out this potential in others, while cruel, malicious and envious states of mind do the opposite. In Buddhist meditation systems, compassion is also closely connected with love, sympathetic joy, and equanimity—called the "four immeasurable attitudes" - as bases for powerful meditative insight. In sum, compassion is viewed as a power for purifying the mind of confusion, for inner healing, and for protection of self and others.

Compassion has been taught and practiced for millennia in three main Buddhist traditions: Theravada, Mahayana, and Vajrayana. These approaches to the alleviation of suffering are more akin to psychology and philosophy than religion insofar as they do not require belief in a higher power to reap their benefits. As clinical scientists and psychotherapists begin to systematically explore the concept of compassion, it may be helpful to consider the nuances in understanding that have emerged within these traditions in different parts of the world.

\section{Compassion in Early Buddhism and Theravada Tradition}

Because compassion in Buddhist psychology involves a wish for beings to be deeply free of their sufferings, Buddhist understandings of "suffering" (Pali dukkha) are crucial to its understanding. Theravada traditions of Southeast Asia, which systematized the early teachings of the Buddha, describe three levels of suffering: obvious suffering, the suffering of transience, and the suffering of self-centered conditioning (Nyanamoli, 1964; Harvey, 1990). Obvious suffering includes all physical and mental forms of misery 
that we normally associate with the word "suffering": the miseries of illness and physical injury, of old age and dying, of grief, mental anguish and distress. The suffering of transience is the futile attempt to get, have and hold onto pleasant things as if they could be a stable source of security and well-being. The passing things to which our minds cling for happiness and security transform into conditions of suffering as we lose them throughout life and inexorably approach death.

The suffering of self-centered conditioning underlies the prior two. This form of suffering is inherent in the mind's subconscious attempt to create from the impermanent flow of its experience the impression of a substantial, unchanging, and separate sense of self surrounded by a stable world. The mind's ongoing attempt to fabricate such a reified, unchanging impression of self and world, in turn, conditions numerous anxious patterns of thought and reaction: clinging to whatever seems to affirm a fixed, unchanging self and its world, fearing or hating whatever seems to threaten it (see Chapter 10). To oscillate uncontrollably through such feelings in reaction to our mental constructs of self and others is the suffering of self-centered conditioning (Makransky, 2007).

The sufferings of transience and self-centered conditioning are not fully conscious to most of us, but the Buddha's process of awakening, it is taught, made him vividly aware of them. The Buddha's compassion, in wishing persons to be free from suffering, focused on all three levels, the last two of which are present even when obvious sufferings are not. For this reason, the Buddha's compassion extended to all beings equally. It is this impartial, unconditional and all-inclusive compassion that the Buddha imparted to his followers. 


\section{Mindfulness}

In the path of awakening explained by the Buddha, mindfulness is key. To cultivate mindfulness is to cultivate conscious awareness of present experience without judgment. As noted, the sufferings of transience and self-centered conditioning are mediated by unconscious habits of reification - the mind's attempt to generate and cling to a sense of permanence in self and world that the mind projects onto its impermanent experience. As our tendencies to cling to illusions of permanence are illuminated by mindful awareness, we become newly conscious of how much anxiety and unease our clinging has generated. We can then start to recognize the same sub-conscious layers of suffering operating in all others. Thus sympathy and compassion for self and others emerge with increasing power as we gain insight into impermanence and the constructed nature of self. Such sympathy and compassion in relation to our selves informs the gentle, accepting quality of mindful attention, giving our mind permission to open to further insight. And this, in turn, helps empower an increasingly compassionate and discerning awareness of others in their conscious and subconscious sufferings.

The inmost causes of suffering diagnosed by the Buddha - the illusion of a reified fixed, unchanging self and the deluded reactions of attachment and aversion that constellate around it - are progressively weakened by such deepening insight, which cuts through the mind's construct of separateness and senses others as fundamentally like oneself, strengthening one's sympathy for them (Fulton, 2005 p. 63). When one is most fully released from inner causes of suffering by such insight, it is taught, nirvana is attained — inmost freedom from the sufferings of self-grasping. As such insight progressively deepens in its realization of nirvana, it also recognizes the commonality of 
self and others in their underlying potential for such inner freedom. The compassion that emerges from that liberating insight, therefore, is not discouraged or depressed by the layers of suffering it senses in beings, but holds them in their potential for deep freedom from suffering. Such compassion does not just uphold others in their underlying potential, but also challenges aspects of their thought and action that hide their potential (Aronson, 1986; Makransky, 2007).

\section{The Eightfold Path}

Compassion is thus implicitly associated with the whole process of awakening that unfolds through deepening mindfulness and insight, which are referred to as right mindfulness and right understanding in the Buddha's eight-fold path of liberation. Compassion is also implicitly related to the other six factors cultivated within the eightfold path: right thought, speech, action, livelihood, effort and concentration. Right thought, informed by insight into selflessness, is thought directed away from grasping, cruelty and ill-will toward compassion and love (Harvey, 2000). Such thought is the power of intent that motivates right speech, right action and right livelihood (Rahula, 1974, Harvey, 2000). And such compassionate thought and activity nuance the sort of effort that is needed to complete this path - the compassionately gentle, caring focus of disciplined energy in mind and body that helps us nurture and sustain wholesome states of mind. Right concentration is the cultivation of deep tranquility through focused attention to a meditation object. To accomplish such concentration, besides other objects of meditation, the Buddha frequently taught intensive meditations of love (Pali metta), compassion (karuna), sympathetic joy (mudita) and equanimity (upekkha) (Aronson, 1986, note 6). When those states of mind are cultivated impartially and all-inclusively in 
meditative concentration, they become the four immeasurable attitudes, which are said to give the mind tremendous power to overcome obstacles, to live with happiness and ease, to support one's progress in all aspects of the path, and to elicit the potential in others for similar states of mind (Aronson, 1986; Harvey, 2000).

\section{The Four Immeasurable Attitudes}

Given such benefits, Theravada Buddhism has emphasized the cultivation of the four immeasurable attitudes, which are explained systematically in Buddhaghosa's classic text The Path of Purification. Here, love (or loving-kindness) is the open-hearted wish for beings to have happiness and well-being. It is not to be confused with selfcentered attachment or possessiveness. Love undercuts tendencies toward ill-will and fear and is thus characterized as a protective power for oneself and protective influence on others.

Love

In the meditative cultivation of love that Buddhaghosa describes, the wish of love is directed first to oneself, since to accept oneself deeply is crucial to the deep acceptance of others, all of whom are like oneself in their layers of suffering and their wish to be happy. First, we generate positive wishes and feelings of love and acceptance for our self by repeating phrases such as: "May I have well-being and happiness; May I be free from enmity and danger." When the wish and feeling of love becomes established in regard to our self, then recognizing how others also wish to be happy, it feels natural to extend the same wish to others. We begin extending the wish to someone who strongly elicits it, such as an especially inspiring teacher or mentor. The wish and feeling of love is next extended to a dear friend. As the power of love for such dear objects emerges, it can be 
harnessed and directed to less obvious objects: first to a neutral person (someone previously viewed as a stranger who now becomes the object of the same loving wish and feeling), then to someone who has been hostile. Increasingly, we recognize every kind of person and living being as like us, a worthy object of love no matter how they superficially appear, and the wish of love is progressively extended until it literally includes all beings everywhere. This draws our mind into a state of deep absorption, with a sense of immeasurable inclusiveness, stability, tranquility, and joy (Nyanamoli, 1964; Aronson, 1980; Salzberg, 1995; Harvey, 2000). This concentration may then be deepened into further levels of meditative absorption. Buddhagosa was the first to fully articulate and systematize this practice, described in Chapter 3 as "loving-kindness meditation.”

\section{Compassion}

Based on this cultivation of love, we are ready to cultivate compassion, the empathic wish for beings to be free from suffering. As a mental power, compassion undercuts tendencies toward cruelty. It is not to be confused with sadness about suffering, since what it wishes for beings - inner freedom from suffering — is seen as a real possibility within the Buddha's path of awakening. Sensing all beings as dear through the practice of love, and reflecting on the sufferings they undergo, compassion for them naturally arises. Because the initial cultivation of love began with love for self, compassionate self-acceptance is also now assumed. Buddhaghosa instructs us to focus first on someone experiencing intense misery since this strongly evokes our compassionate wish for the other person to be free from suffering. We then direct our mind with the same empathetic feeling and wish of compassion to a friend, then a neutral 
person, then someone who has been hostile. Finally, as with immeasurable love, the mind of compassion is extended to all beings everywhere - becoming all-inclusive, stable, and joyful as it deepens into increasingly subtle levels of meditative absorption. We can focus compassion on all sentient beings, including those who are not presently experiencing obvious misery, by recalling their ever-present sufferings of transience and self-centered conditioning (Nyanamoli, 1964; Harvey, 2000).

\section{Sympathetic Joy}

Love and compassion for living beings naturally evoke our joy in their happiness and good fortune, and so the next cultivation is that of sympathetic joy. Sympathetic joy, which takes quiet joy in the happiness of others-rather than becoming overexcited or giddy - undercuts tendencies toward jealousy and aversion when others may be doing better than we are. In practice, we reflect first on the happiness and success of a dear friend, taking joy in the friend's happiness with thoughts like, "How wonderful! How fine!" We then turn our mind to the happiness of a neutral person, then to one who has been hostile, and finally to all beings everywhere.

\section{Equanimity}

Equanimity is a peaceful calmness in the face of the ups and downs that all beings undergo, recognizing that their potential for happiness and suffering is conditioned by their own patterns of intention and reaction to experiences (Harvey, 2000). Equanimity is also the power of impartiality that senses all beings as essentially the same in their layers of suffering and their wish and potential for freedom from distress. It thus supports the impartial extension of love, compassion and sympathetic joy to all. Although equanimity undercuts partiality, it is not to be confused with apathy. The cultivation of equanimity 
focuses first on a neutral person, then a dear one, a deeply revered friend, a hostile person, and finally all beings everywhere. Such immeasurable equanimity, Buddhagosa says, is established on the highest level of meditative absorption, based on previous levels of absorption that were attained in the prior three meditations (Nyanamoli, 1964).

The blending of equanimity with the other "immeasurable attitudes" helps to maintain their purity. For example, equanimity protects love from unnecessary clinging to the object of affection; equanimity protects compassion from a sense of inequality or pity, and equanimity protects sympathetic joy from comparing oneself unfavorably to another. And as mentioned in Chapter 3, equanimity as a state of mind is also associated with wisdom.

The four immeasurable attitudes of love, compassion, joy and equanimity, cultivated in this way, are also referred to as the "four divine abodes," states of mind akin to those of a god in ancient Indian lore. Thus, in early Buddhist and Theravada understanding, compassion is most fully realized when cultivated in close connection with the related attitudes of love, joy and equanimity. Together, they constitute an ancient and highminded "positive psychology"- the happiness of the gods

\section{Compassion in Mahayana Buddhism}

The Theravada path of awakening noted above is modeled on practices of accomplished disciples of the Buddha known as arhats, those who are said to have attained nirvana, inner liberation from suffering. Although, as noted above, compassion in Theravada Buddhism is implicitly related to each part of the path, it was not given the same central importance as wisdom, the insight that explicitly liberates from suffering. 
Because insight or wisdom recognizes the impermanent, selfless nature of experience, it alone releases the mind from its tendencies to reify and cling to its constructed sense of self, freeing us from inmost causes of suffering. Therefore insight, rather than compassion per se, is upheld as the core liberating principle of the Theravada path of the arhats (Aronson, 1980).

Other movements in the development of Indian Buddhism emerged from the first century BCE that constellated under the term "Mahayana," the "Great Vehicle." Mahayana traditions gave compassion a greater centrality because they placed a fresh emphasis on the kind of awakening that the Buddha had realized that set him apart from other arhats. The Buddha's realization gave him the power skillfully to communicate the insight of his awakening in ways that benefited countless people over many generations. Indeed, the Buddha's power to beneficially affect others through the power of his presence and speech, exceeding other arhats, was taken as an indication that the Buddha's wisdom also far exceeded theirs. For his wisdom not only freed himself from causes of suffering but enabled him to point so many others to the same essential freedom. The Buddha's long prior training in impartial compassion was viewed as the means by which he deepened his wisdom to the point that he could know others so profoundly and teach them so skillfully. Compassion is thus raised up in Mahayana traditions as ultimately inseparable from wisdom within the fullest form of awakening (Harvey, 2000). Those who choose to follow the Buddha's own distinctive path of awakening — to realize and communicate the inseparability of wisdom and compassion for the sake of the world-are called bodhisattvas. 


\section{Compassion and Emptiness}

The wisdom taught in Mahayana traditions opens us to others in compassionate intimacy not only through insight into their condition but also through recognition of the ultimately undivided nature of all that exists. According to Mahayana teachings, not only are phenomena found to be impermanent and beyond reification into "me" or "mine" (as in Theravada), but upon further investigation, no independently existent phenomenon of any kind, impermanent or otherwise, is even findable. So, for example, a wooden table initially appears to us as an intrinsically unified entity that seems to exist of itself, independently, as though unrelated to prior causes, conditions or parts and as if it had nothing to do with the constructive activity of the observer's mind. But upon investigation, Mahayana texts assert, no such independently existent table can be foundinstead, the table can be analyzed into innumerable causes, conditions and parts that have been cognitively organized into the appearance of a separate, self-existent "table" through the conceptual construction of the observing mind.

On the level of appearances, this means that the wooden table can not be separated from all the causes and conditions that contribute to its existence: a carpenter, trees, atmosphere, sunlight, soil, water, earthworms, insects, etc., each of which exists in dependence upon further innumerable causes and conditions that finally relate each thing to all other things, and each sentient being to all other beings. On the level of deep insight, no independent, separate thing can be found anywhere-every seemingly separate "thing" is empty (Sanskrit: sunya) of the sort of isolated self-existence that it appeared to have prior to such deep investigation. 
In Mahayana Buddhist understanding, the insight that thus recognizes phenomena to be empty of self-existence cuts even more deeply into the inner causes of suffering than the insight into impermanence-more fully deconstructing the tendency to reify and cling to experiences, since the wisdom of emptiness doesn't find any independent thing to which even impermanence can be ascribed. To thus realize the empty nature of phenomena is to go beyond even the reified conceptual construct of a separate "observer" and "observed," to relax into a non-conceptual, non-dual awareness that recognizes the entire world and its beings as ultimately like undivided space (Conze, 1973). This is not a form of nihilism, for things continue to appear through the force of their interdependently generated modes of existence, and beings continue to suffer by reifying, clinging, and reacting to things and each other, as if they were all inherently separate and self-existent — as if they were not empty. Rather, the non-dual wisdom of emptiness recognizes all beings as undivided from oneself in the empty, inter-dependent ground of all things (Sanskrit dharmadhatu), which supports an all-embracing, unconditional compassion for all creatures.

To realize the emptiness of the world in this way is to realize that nirvana, the empty essence of experiences, is undivided from the world of inter-dependent, changing appearances, like space is undivided from all the forms that it pervades. To realize emptiness thus gives one the freedom to participate in the world without clinging to it, with unconditional compassion for all who suffer by clinging and reacting to their own concretized projections of self and other as self-existent. As one scholar notes, "[This] means, for example, that a bodhisattva can rub shoulders with wrong-doers, to reach them and draw them toward the good, as he knows that their bad characteristics are not 
inherent realities" (Harvey, 1990, p. 125). Such radical compassion is also essential when practicing psychotherapy—especially with those who cause harm to others.

To have non-conceptual insight into emptiness (Sanskrit sunyata) then, beyond all reification and grasping (and thus beyond the inner causes of suffering) is to feel tremendous compassion for all persons who continue to be caught in causes of suffering and who are sensed as ultimately undivided from oneself. That profound insight as basis for such all-inclusive compassion is called the perfection of wisdom (Sanskrit prajnaparamita).

\section{The Six Perfections}

In early Mahayana texts, the four immeasurable attitudes of love, compassion, joy, and equanimity are freshly articulated in line with these teachings. Deepest equanimity is now identified with the perfection of wisdom itself — which is intrinsically stable, tranquil, and free of expectation or partiality because it is grounded in the unconditioned, undivided, empty nature of things beyond discrimination (Conze, 1973, 1979). The love, compassion and sympathetic joy that radiate from such wisdom, aware of how beings suffer by clinging to their experiences, motivate actions to meet each level of their need and ultimately to point them to complete freedom. Such activity is described as "generous, disciplined, patient, indefatigable, and deeply grounded" (Conze, 1973 p.

199). Those five paradigmatic aspects of other-directed activity, together with the perfection of wisdom that informs them, are the six perfections that comprise the bodhisattva path of awakening. 


\section{Cultivating Wisdom and Compassion Together}

Although we all have the potential to realize the perfection of wisdom, our entrenched tendencies to cling to things as intrinsically separate and self-existent make it difficult for us to move beyond a merely conceptual understanding of such teachings to a non-conceptual, non-dual realization of their meaning that can profoundly transform our responses to others. Since all-inclusive compassion is the primary response of non-dual wisdom to the world, to train in such compassion before we have directly realized that wisdom is to harmonize the mind with its potential for that wisdom. In other words, to cultivate universal compassion helps release the mind from the narrow confines of its clinging to self and to dualism, giving it the courage and power to release its frames of reference into the boundless emptiness of non-conceptual wisdom. To cultivate the wisdom of boundless, undivided emptiness, in turn, further empowers an analogously boundless, impartial compassion (Harvey, 1990; Makransky, 2007). So, in Mahayana traditions from India, practitioners train extensively in meditations of compassion to empower their minds to realize non-conceptual wisdom, and as non-conceptual wisdom emerges, it is harnessed to strengthen compassion.

The systematic cultivation of compassion and wisdom is explained in a group of texts called The Stages of Meditation by the eighth century Indian Mahayana teacher Kamalasila. He gives instruction on cultivating compassion for dear, neutral, and hostile persons, culminating in compassion for all beings everywhere. At each stage, we reflect on the sameness of self and others in their three levels of suffering and in their wish to be free of misery. We also reflect on our relation to all others through inter-dependent connection, and endeavor to learn to view everyone equally as our own suffering family. 
As you may notice, this meditation is similar to Theravada cultivation of compassion, but in the Mahayana tradition the force of compassion is immediately channeled into a strong aspiration to attain a buddha's awakening with the skillful means to help all others find freedom from suffering. This aspiration is called the spirit of enlightenment (bodhicitta), and is reinforced by the bodhisattva vow to fully realize the skillful means of compassion and wisdom for the sake of all (Beyer, 1974). Empowered by that solemn vow, the bodhisattva enters stages of meditative concentration that give the mind enough stability to investigate the insubstantial nature of all aspects of experience until non-conceptual wisdom dawns. This dawning wisdom of emptiness strengthens the bodhisattva's compassion for all who suffer by clinging to what is empty (Beyer, 1974 p. 110), which empowers his or her mind to release itself further into the wisdom. This synergy of compassion and wisdom is worked out through the bodhisattva's practice of the six perfections on the path to buddhahood - at each stage compassionately offering his or her time, energy, patience, resources, and power of presence in whatever ways may help ease and release the suffering of beings, while recognizing the empty nature of all such activity.

In Tibetan Mahayana training systems that draw on such Indian systems of praxis, compassion is cultivated by recalling one's mother as a source of loving kindness, eliciting one's natural response of love in return. This loving response is then transferred to all beings as past mothers, whose suffering in all three levels becomes the object of one's all-inclusive compassion. Such compassion evokes one's aspiration to help beings find freedom from suffering by helping them fully realize their potential (Harvey, 2000; Makransky, 2007). 


\section{Exchanging Self and Other}

Another renowned $8^{\text {th }}$ century Indian teacher, Santideva, by pointing out the constructed nature of concepts of "self" and "other," shows us how to re-employ those concepts to re-configure our world into an expression of compassion and wisdom, entering into the bodhisattva path. "Self" and "other" are merely relative, contextual terms, Santideva argues, like "this bank" and "the other bank" of a river. Neither side of a river is intrinsically an "other bank." (Harvey, 2000). Similarly, it is a cognitive error to think of other beings as intrinsically "other." For all are "self" from their own perspectives; all are like oneself in their deepest potential, desire for happiness, and deluded patterning; and all are undivided from oneself in the empty, inter-dependent ground of all things (Wallace and Wallace, 1997). By reflecting on the sameness of self and others in such ways, and the tremendous benefit to our mind that would come by reversing the usual constructs of "self," "other" and associated feelings, we explore viewing others as our very self while sensing our self as a neutral other. Through such practice, we discover, the great burden and suffering of clinging to our self over others is relieved, and we can increasingly give rise to the compassion and wisdom that feels and recognizes all beings as like ourselves (Wallace and Wallace, 1997).

In Tibet this practice of "exchanging self and other" is commonly given the form of tong-len meditation, in which we exchange self for other by imagining that we take others' sufferings into the empty ground of our being while freely offering others all of our own virtue, well-being and resources. This imaginative pattern helps conform our mind to the wisdom of emptiness that recognizes others as ultimately undivided from our self, and gives that wisdom its most fundamental compassionate expression (Chodron, 
2001). Part of the power of tong-len is the way it is also applied to recontextualize and transform our own experiences of suffering. When we undergo difficulties, we sense right through our own suffering the analogous suffering that many others undergo, then imagine joyfully relieving those others of their suffering by undergoing our own on their behalf. People tend to experience the grief of loss, for example, as isolating them from others. But in this practice, through our own feelings of loss and grief, we sense what many others feel, making a strong empathetic connection to them. And this helps our mind further release its grip on its isolated sense of self, to relax into the empty essence of experience, to sense the ultimate undividedness of self and other, and thus to become more fully present to others in relationship and service. By familiarizing with applied tong-len in this way, we can gradually learn to take all of our own suffering into the path of compassion and wisdom even unto death (Chodron, 2001; Makransky, 2007).

\section{Compassion in Vajrayana (Tantric) Buddhism}

Further traditions of Buddhism emerged in India from the eighth century CE that came to be called "Vajrayana" ("Diamond Vehicle"), which became central within the spread of Buddhism to Tibet and Himalayan regions of Asia. Based in part on the teachings above, some Mahayana schools had posited that a tremendous capacity for compassion and wisdom, and for all associated qualities of awakening, is innate—already given in the deepest, unconditioned nature of our minds. Vajrayana traditions put special emphasis on this teaching of Buddha nature, in relation to which the foundational teachings of suffering and its causes were reframed. 


\section{Our Buddha Nature}

Our fundamental awareness, Vajrayana asserts, prior to all patterns of selfcentered clinging, is essentially unconditioned, pure and undefiled. Our basic awareness is a limitless expanse of emptiness and cognizance, like boundless space pervaded by sunlight, already endowed with all-encompassing wisdom and compassion. Individual and socially conditioned habits of reification and grasping have hidden much of this underlying potential. To cultivate compassion and wisdom, therefore, is not to generate new states of mind and make them grow stronger (as was understood in Theravada and some earlier Mahayana traditions), but rather to help the mind relinquish its deluded tendencies so that its innate, unconditioned power of boundless compassion and wisdom, its Buddha nature, can spontaneously manifest. Holding this vision in awareness, a psychotherapist can nourish and support a patient's deepest nature, regardless of the prevailing emotional struggle.

The deep primordial nature of mind, Vajrayana thus asserts, contains all positive energies and qualities of awakening in potential. When a person's attention is habitually caught in patterns of self-centered thought and reaction, those innate energies become patterned into deluded emotions like fear, possessiveness and aversion-into inner causes of suffering (Bokar Rinpoche, 1991). Vajrayana practice is designed to transform and liberate these confused patterns of emotion by letting one's innate, primordial awareness recognize all experiences as expressions of its own empty cognizance, beyond reification or clinging. When one's innate awareness recognizes thoughts and emotions as patterns of its own cognizant emptiness, emotions spontaneously self-release within their own unconditioned emptiness, like writing on water dissolving back into its own unchanging 
wateriness. Then the innate energies that had fueled deluded emotions are freed from their distorted patterning to manifest as energies of all-inclusive compassion, wisdom and presence to others (Dilgo Khyentse Rinpoche, 1992; Sogyal Rinpoche, 2002; Makransky, 2007; Ray, 2001). Compassion is thus understood as an intrinsic capacity of fundamental awareness - an innate quality of primordial mind that is unleashed automatically when the mind is freed from its habitual patterns of self-centered conceptualization and reaction.

Because all persons share this same innate capacity for spontaneous awakening, the compassion of a Vajrayana practitioner knows other beings not only in their suffering but also in their immeasurable dignity, primordial purity and innate potential. Someone who has actualized his or her Buddha nature, then, communes with the unactualized Buddha nature in other persons, mirroring their deepest potential back at them and thereby helping to evoke it in them (Makransky, 2007). Awakening to one's own innate potential becomes infectious.

Tibetan Vajrayana meditation practice embodies this infectiousness. We bring to mind a host of awakened benefactors, in human or symbolic form, whom we regard as embodiments of deepest compassion and wisdom, of actualized Buddha nature. We commune deeply with these compassionate figures, ritually offering all of our outer and inner experiences to the Buddha nature that they represent. Held within their pervasive compassion and wisdom, our own layers of suffering can now be experienced with a sense of deep acceptance and safety, helping us to release the grip of our emotional patterning, finally to merge with our benefactors in the ground of their pervasive compassion, Buddha nature, the limitless expanse of emptiness and cognizance 
(Thondup, 1995). From that place, our own innate capacity can now be unleashed-our compassion for all others in their analogous layers of suffering and underlying potential can spontaneously unfold. As we learn in this gentle way to come into recognition of our Buddha nature and to extend its compassionate energy to all others, we learn to take our own place among awakened benefactors and become an extension of their activity for all beings (Dilgo Khyentse Rinpoche, 1992; Bokar Rinpoche, 1991; Makransky, 2007).

In summary, compassion and wisdom are inter-related in varying ways within three leading Buddhist traditions. In early and Theravada Buddhism, compassion is a power for deep mental purification, protection, and healing that can support inner freedom. In Mahayana Buddhism, compassion becomes the primary means to empower and communicate a non-conceptual wisdom in which self and others are experienced as undivided. In Vajrayana Buddhism, unconditional compassion radiates forth allinclusively as a spontaneous expression of the mind's deepest unconditioned nature.

Systematic ways of cultivating wise compassion have been developed within each tradition. In our modern global culture, clinicians have the opportunity to explore which approach is most suitable for themselves or their psychotherapy clients. In consultation with experienced teachers of these meditation traditions, clinicians can also explore how existing concepts and techniques may be adapted to their settings. May this book foster and facilitate that noble effort. 


\section{REFERENCES}

Aronson (1980). Love and Sympathy in Theravada Buddhism. Delhi: Motilal

Banarsidass.

Beyer, Stephen (Translator). (1974). The Meditations of a Bodhisattva: Kamalasila's

Bhavanakrama. S. Beyer (Editor and Translator), The Buddhist Experience:

Sources and Interpretations. Encino, CA: Dickenson Publishing Co.

Bokar Rinpoche (1991). Chenrezig, Lord of Love: Principles and Methods of Deity

Meditation. San Francisco, CA: ClearPoint Press.

Carter, John Ross and Palihawadana, Mahinda (Editors and translators). (1987). The

Dhammapada. New York: Oxford University Press (chapter 1, verses 1 and 2 are retranslated here from the Pali by John Makransky).

Chodron, Pema (2001). Start Where You Are: A Guide to Compassionate Living.

Boston, MA: Shambhala Publications.

Conze, Edward (Translator). (1973). The Perfection of Wisdom in eight Thought Lines and Its Verse Summary. Bolinas, CA: Four Seasons Foundation.

Conze, Edward (Translator). (1979). The Large Sutra on Perfect Wisdom with the Divisions of the Abhisamayalankara. Delhi: Motilal Banarsidass.

Dilgo Khyentse Rinpoche (1992). The Heart Treasure of the Enlightened Ones. Boston, MA: Shambhala Publications.

Fulton, Paul (2005). Mindfulness as Clinical Training. In C. Germer, R. Siegel, and P. Fulton (Eds.), Mindfulness and Psychotherapy (pp. 55-72). New York: Guilford. Harvey, Peter (1990). An Introduction to Buddhism: Teachings, History and Practices. New York: Cambridge University Press. 
Harvey, Peter (2000). An Introduction to Buddhist Ethics. New York: Cambridge University Press.

Makransky, John (2007). Awakening through Love: Unveiling Your Deepest Goodness. Boston, MA: Wisdom Publications.

Nyanamoli , Bhikku (Translator). (1964). The Path of Purification (Visuddhimagga) by Buddhaghosa. Colombo, Ceylon: A. Semage Publications.

Wallace, Allan and Wallace, Vesna (Translators). (1997). A Guide to the Bodhisattva Way of Live by Santideva. Ithaca, NY: Snow Lion Publications.

Rahula, Walpola (1974). What the Buddha Taught. New York: Grove Weidenfeld. Ray, Reginald (2001). Secret of the Vajra World: The Tantric Buddhism of Tibet. Boston, MA: Shambhala Publications.

Salzberg, Sharon (1995). Loving-Kindness: The Revolutionary Art of Happiness. Boston, MA: Shambhala Publications.

Sogyal Rinpoche (2002). The Tibetan Book of Living and Dying. New York: Harper Collins.

Thondup, Tulku (1995). Enlightened Journey: Buddhist Practice as Daily Life. Boston, MA: Shambhala Publications 